\title{
Ambient Intelligence 2.0: Towards Synergetic Prosperity
}

\author{
Emile Aarts ${ }^{\mathrm{a}, *}$ and Frits Grotenhuis ${ }^{\mathrm{b}}$ \\ ${ }^{a}$ Philips Research, High Tech Campus 34, 5656AE, Eindhoven, The Netherlands \\ ${ }^{\mathrm{b}}$ Grotenhuis Organisatieadvies BV, P.O. Box 3199, 3760DD, Soest, The Netherlands \\ E-mail:frits@grotenhuisadviseert.nl
}

\begin{abstract}
Ten years of research in Ambient Intelligence have revealed that the original ideas and assertions about the way the concept should develop no longer hold and should be substantially revised. Early scenario's in Ambient Intelligence envisioned a world in which individuals could maximally exploit personalized, context aware, wireless devices thus enabling them to become maximally productive, while living at an unprecedented pace. Environments would become smart and proactive, enriching and enhancing the experience of participants thus supporting maximum leisure possibly even at the risk of alienation. New insights have revealed that these brave new world scenarios are no longer desirable and that people are more in for a balanced approach in which technology should serve people instead of driving them to the max. This novel approach is called Synergetic Prosperity, referring to meaningful digital solutions that balance mind and body, and community and earth thus contributing to a prosperous and sustainable development of mankind.
\end{abstract}

Keywords: People-Centric Design, Ambient Intelligence, Synergetic Prosperity

\section{Developing Ambient Intelligence}

Ambient Intelligence (AmI) is about creating environments that are sensitive and responsive to the presence of people [1]. The user of all new AmI technologies is placed in the centre of the environment moving technology into the background. The concept aims at taking the original Ubiquitous Computing ideas of Mark Weiser [2] one step further in the sense that users are centrally positioned and devices are fully integrated into their physical environments, In 2001, the Information Society Technology Advisory Group (ISTAG) of the European Commission [3] proposed the concept of Ambient Intelligence to be used as the central theme for the $6^{\text {th }}$ Framework Program in IST. Several years later, ISTAG described Ambient Intelligence as 'a stable, yet evolving vision' [4]. Over the years, Ambient Intelligence developed itself primarily as a technology enabler for participation of users in society.
On the one hand, the AmI vision promises many exciting opportunities. On the other hand, several new issues related to the vision have surfaced that need to be dealt with, related to social, business, and technological aspects. Many different papers and books address such aspects and visions on Ambient Intelligence. The New Everyday by Aarts and Marzano [5], for instance, provides a broad overview of directions and major questions in Ambient Intelligence. Today, for some of these questions there are appropriate answers, but most of them have not been adequately addressed, however.

In their book 'True Visions', Aarts and Encarnacao [6] recognize the early stage of Ambient Intelligence from where we are in a transition stage, from 'articulating and evangelizing' the vision towards its implementation, where different challenges have risen. Many relevant aspects of Ambient Intelligence are discussed and elaborated thus presenting a good overview of the state of the art of the technology de-

\footnotetext{
${ }^{*}$ Corresponding author. E-mail: emile.aarts@philips.com.
} 
velopments that have been accomplished. At the same time the authors argue that we are still a great leap away from Ambient Intelligence being fully accepted and integrated in our daily lives. Aarts and Encarnacao describe two parallel research tracks that should be followed in order to realize the vision:

1. The further development of specific technologies, and

2. The development and implementation of AmI scenarios in which user needs, preferences, and cultural demands are leading.

Major challenges in Ambient Intelligence until today are the use of the physical world as the interface, the development of smart environments, the development of environmental programming, the problem of making environments situational aware, giving environments the ability to handle context, and eventually to master the experience itself. In the next decade, the challenge is not so much to embed Ambient Intelligence into people's lives, but more importantly will it to be able to find answers to provide people with ambient solutions that address their real-life problems.

More recently in 2009, ISTAG issued a Report on Revising Europe's ICT Strategy [7] where they analyze individual, business, and societal trends, as well as ICT trends and their impact. Based on these insights ISTAG developed a vision for future ICT related to sustainability, productivity, and society. For Ambient Intelligence this implies that social intelligence and design are being recognized as crucial aspects next to cognitive intelligence and computing.

In conclusion, the development of Ambient Intelligence shows real progress, but at the same time it calls for a repositioning of the vision in terms of its application. Despite all efforts and intentions, the major challenge in Ambient Intelligence remains the understanding and anticipating of what people really want and to build solutions that really impact their lives.

\section{Towards People-Centric Design}

Aarts and Diederiks [8] report in 'Ambient Lifestyle: from Concept to Experience' on five years of research in ExperienceLab, the experience and application research center of Philips. More than forty projects from the Philips Research Laboratories are described. They report on of few killer applications of which the AmbI Light television is by far the most successful one. Several concepts were transferred into incubator projects leading to startup companies including amBX, Serious Toys, and Lumalive. Nevertheless, most concepts developed in ExperienceLab did not lead to any business activity, for the simple reason that it could not be made clear what the true added value for people would be and which business model should be applied to put the concept in the market.

Generally speaking, the promise of Ambient Intelligence of a truly user centered technology has not been fulfilled over the past decade. The major reason is that most of the newly proposed prototypes are still based on what is known as technology-push, despite new approaches such as user-centric design. They are still not focused at solving real problems and they are still too deeply rooted in the classical western materialistic needs. Ambient Intelligence can significantly contribute to the development of a sustainable society through its dematerialized approach to technology resulting from the full embedding of devices in its environment.

Green has identified this new opportunity by stating [9]: "The dematerialization of happiness is matched by the ability of the new ambient technologies to dematerialize benefits". Context has become more important than consumption. People should be the drivers, where ambient technology is enabling. Ultimately, only users know and determine what makes sense, what really provides value to them.

\section{The People Age [9]}

"Just as the industrial era was characterized by consumption, so the next era will be characterized by context. The industrial era is giving away to a new economy, based more on knowledge and context than on material assets and consumption. While some call this the Knowledge Age, perhaps it would be simpler and more sense-making to call it the People Age. The democratization of information, production, and power means inevitably that people are becoming the principal drivers and actors of their own futures, aided and abetted by the flexibility and adaptability of the new technologies. It is people who generate knowledge, and not only knowledge, but also creativity, imagination and sense of purpose, all qualities that we need as we go forward. As people, rather than the economy or technology, drive the future, so the emphasis in terms of why we do things, what we do and how we do them is shifting". 
In order to better understand what people want or need, different forms of research have been practiced. To this end, the so-called Experience Research approach was developed which identifies three levels of user-centric research: Experience@Context, Experience@Laboratory, and Experience@Field [10]. This approach is useful in separating concerns, i.e., needs from solutions and controlled from uncontrolled user studies.

Research into AmI products and services introduces the need for test infrastructures that can be used to involve people who will be using those products and services in the early stages of the development. Only by such an approach AmI products and services will be adopted eventually by users. Experience and Research is a means to organize this peoplecentric $\mathrm{R} \& \mathrm{D}$ process.

The major new aspect, compared to previous testing of existing products and services, is that users are involved from the very beginning of research and development through the whole lifecycle. Within Experience Research different types can be discerned: user-related research, development of prototypes, usability tests, and feasibility tests and validation [11]. Experience Research offers new opportunities for multidisciplinary centers of excellence for research, development, and design.

Living Labs are another recent means to better understand what factors make innovation successful in relation to different environmental, social and cultural settings. They can be defined as: "Collaborations of public-private-civic partnerships in which stakeholders co-create new products, services, businesses and technologies in real life environments and virtual networks in multi-contextual spheres" [12]. They can be seen as a new and promising instrument for communities conducting Experience Research.

\section{The 'dark side' of Ambient Intelligence}

Next to the many positive advances and perspectives of Ambient Intelligence, criticism has surfaced leading to a counteracting movement. People have started to investigate the consequences of the AmI vision and its implementation. Many relevant issues have been raised that need to be resolved in an AmI world such as, for instance, property rights on personal data or virtual identities [13].

In 2005 the European Commission launched the SWAMI (Safeguards in a World of Ambient Intelligence) project [14], in order to identify and analyze issues in relation to the 'dark side' of Ambient Intel- ligence in a structured way. As a result, Wright et al. [15] present in their book 'Safeguards in a World of Ambient Intelligence' a direct warning about the threats in current and future developments in Ambient Intelligence. After years of positive news about the technological potential, issues were addressed regarding the vulnerabilities of Ambient Intelligence related to important social issues such as privacy, identity, trust, security, and inclusion.

Gary Marx describes two major risks in his foreword of the book: bad or incompetent people and/or organizations with good technology, and good people and/or organizations with bad or inappropriate technology. The SWAMI group developed four 'dark' scenarios to illustrate their concerns. These scenarios have had both a technology check (regarding probability of referenced technologies) as well as a reality check (regarding similarities to existing press reports).

Wright et al. conclude that an ambient intelligent world can only be successful if all stakeholders recognize the threats and vulnerabilities, and cooperate in ensuring the necessary technological, socioeconomic, and legal and regulatory safeguards. The SWAMI project has played an important role in integrating these early warning signals in new research projects, as well as in policy making. It is our true conviction that these warnings should be taken very seriously in the future development of Ambient Intelligence.

\section{Dark Scenarios [15]}

"Dark Scenario 1, the AmI family, presents AmI vulnerabilities in the life of a typical family moving through different environments. It introduces dark situations in the smart home, at work and during a lunch break in a park.

Dark Scenario 2, a crash in AmI space, also references a family but focuses more specifically on senior citizens on a bus tour. An exploited vulnerability in the traffic system causes an accident, raising many different problems related to both AmI based travel and health systems.

Dark Scenario 3, what is a data aggregator to $d o$, involves a data-aggregating company that becomes victim of theft of personal data which it has compiled from AmI networks and which fuel its core business. Given its dominant position in the market, the company wants to cover this up but ends up in court two years later. The scenario draws attention to the digital divide between de- 
veloped countries with AmI networks and developing countries that do not have such networks.

Dark Scenario 4, an early morning TV programme reports on AmI, portrays an AmI risk society from the studios of a morning news programme. It presents an action group against personalized profiling, the digital divide at a global scale and related to environmental concerns, the possible vulnerabilities of AmI-based traffic management systems and crowd control in an AmI environment".

\section{More on scenarios in Ambient Intelligence}

Ducatel et al., [16] developed in 2001 visions on Ambient Intelligence for the year 2010 influencing work and daily life of people. The Information Society Technologies Advisory Group commissioned four different possible scenarios. The results of these scenarios were used at that time to structure the discussions about ICT research under the sixth framework.

Next to future technology requirements, Ducatel et al., also took business, economic, and sociopolitical implications into account. Regarding business and economic issues, they considered new business models that will be needed to adjust to changing customer demands, and they analyzed the competitive landscape that will evolve accordingly. Concerning socio-political impact, they addressed issues related to privacy, control and social cohesion. In their scenario analysis they used contrasting dimensions such as economic and personal efficiency versus sociability (goals), and communal versus individual (actors). These differentials resulted in four types of scenarios for Ambient Intelligence in the year 2010.

The first scenario is about 'Maria', a successful business woman, who travels to a Far Eastern country for a business meeting. With the help of ambient technologies, 'a personal and ambient communicator', she is able to manage her trip in a very efficient and personal way, both under way as well as on location while being in (virtual) touch with her family. Upon its introduction almost ten years ago, this scenario was quite compelling because it referred to a solution that could be readily achieved. Actually, by now it became reality to a large extent with the Blackberry and I-phone giving people access to context-aware services, enabling them to schedule or change a flight or hotel, videoconference with clients or family members, and so on.
The second scenario, about 'Dimitrios' and his 'Digital Me', deals with connectivity of people and different identities. This scenario is also close to realization through the recent development of virtual and augmented technologies, allowing people to live a separate digital life, but at the same time to integrate real and virtual worlds.

The other two scenarios are further out in time. The third scenario 'Carmen' is about intelligent traffic systems and the fourth scenario 'Annette and Solomon' predicts shared presence, enhancing social learning by digital connection and a collective community memory. For these two latter scenarios large infrastructural changes would be required, next to the complexity of social, economic, and political aspects that need to be dealt with. This pushes the implementation of these scenarios further out in time.

Five technology requirements were extracted from the four scenarios: very unobtrusive hardware, a seamless mobile and or fixed communication infrastructure, dynamic and massively distributed device network, natural user interfaces, and dependability and security. However, the real question is, is this what we want: ambient technology that enables us to have even busier lives?

One can argue that the ISTAG scenarios have played a significant role in the development of Ambient Intelligence over the past years towards 2010, giving direction to the community's thinking, especially in the technology domain. One may, however, question whether the scenarios still reflect the way people want to live by 2010 . In our opinion this is indeed not the case; there are strong indications that people have shifted their desires profoundly. This is partly due to the current financial crisis and partly due to the growing awareness that a sustainable development of our society calls for an approach different from the technology push of the past decades. The key issue is that AmI solutions simply should make sense. Technology should support and enable meaningful balanced lives. After a decade of developing and experimenting with the AmI vision, we need a new paradigm.

\section{Visions of a new paradigm}

Ambient Intelligence should be implemented in people's lives in such a way that technology enables what people really want. Therefore the innovative playground needs to be repositioned. To this end we use three basic elements, i.e. People, Planet, and 


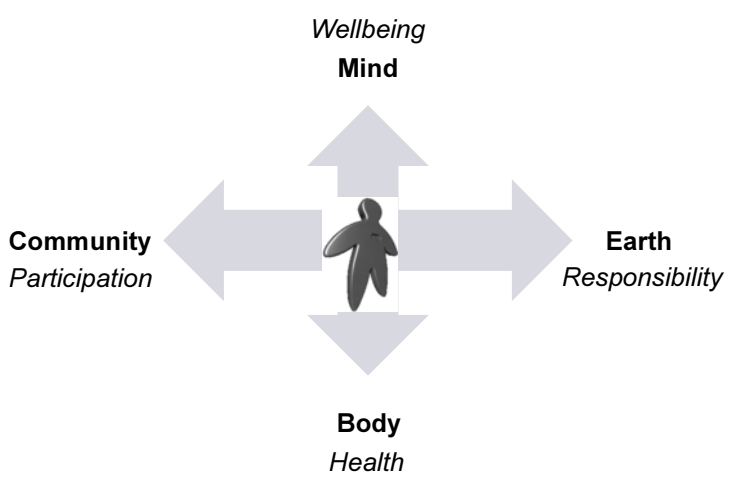

Fig. 1. Putting people in the center of Synergetic Prosperity.

Profit that have been frequently used to describe innovation. Synergetic Prosperity is about the balance between these elements. Only in the presence of a balanced situation, Ambient Intelligence can truly contribute, using its inherent properties such as its dematerialized embedding and its ability to tailor towards people's needs. The basic elements of Synergetic Prosperity are presented in Fig. 1.

Using People, Planet, and Profit as the basic elements we introduce the following views.

People reflects Body and Mind and the needs resulting from them in terms of health and wellbeing. The Latin saying 'mens sanem in corpe sanem' (a healthy mind in a healthy body) already recognized the relation between both.

'Body' is directly related to Personal Healthcare and is concerned with diagnostics, monitoring, and treatment of diseases in a way that is tailored to the individual patient. Personal healthcare addresses sustainable healthcare solutions in which the patient outcome and the quality of life play a central role. Health care has become more and more personal over the past years. The concept of ambient assisted living plays an important role in this perspective.

'Mind' is related to Balanced Lifestyle and focuses on an integral way that brings peace of mind in a demanding society. Balanced lifestyle addresses the need to cope with the personal, mental, and physical demands of a modern lifestyle. In this perspective, Antonovsky [17] discerns between pathogenesis and salutogenesis. Pathogenesis looks at health from a disease point implying a binary state of a person being either sick or well. Salutogenesis applies a more continuous scale to a person's health condition, representing a mixture of elements related to our general state, such as happiness, motivation, and coping with change.
Planet reflects Environment and Community, where Environment can be viewed as the Body, and Community as the (collective) Mind. Community and Environment refer to our participation and responsibility towards our Planet.

'Community' refers to common welfare and taking care of each other. Every person should be able to participate and to make use of his or her capabilities, and so to contribute to our society. Due to globalization and the Internet, society has become more and more open over the past decades. Furthermore, our economy has developed over time from agricultural, via industrial to knowledge based. In the current knowledge-based society, the so-called creative class plays a major role. From this perspective, creative industries focus on creating and exploiting creative services in an open societal setting where every person can participate into. Creative Industries are not only consisting of a white elite part of our population, as some criticisms may like us to believe. In contrast, also in many developing countries creative industries play a major role in economic growth and (digital) infrastructure. Think about the rapidly growing mobile phone network in Africa, or the rise of creative industries in Indonesia contributing 6,3\% on average to the GDP between 2002-2006 [18].

'Environment' relates to sustainable development of the planet which demands a global change in the use of resources in such a way that their use is consistent with future as well as present needs. Sustainable development is about meeting the needs of the present generation without comprising the needs of future generations. Evidently, the issue of the development of a more sustainable planet was brought to the attention of society in the large by $\mathrm{Al}$ Gore in his compelling movie "An Inconvenient Truth" a few years ago. In the mean time there is a rapidly growing group of people called the Cultural Creatives who are challenging materialistic lifestyles and asking for a sustainable alternative building upon novel concepts such as Cradle-to-Cradle, referring to the alignment of industry and environment. Andrew Price introduces the concept of Slow Tech in his recent book offering us an alternative vision on the use of technology in the twenty-first century [19].

Profit should be replaced with Prosperity. True prosperity may result from the right mixture of the various components related to People and Planet as described above. It is important to note that in our view the components related to the components People (Mind and Body) and to Planet (Community and Environment), respectively, are intertwined and inter- 
related in the sense that they reflect two different views of the corresponding elements, but they cannot be separated and consequently should be balanced. The aspect of balancing can be well understood from the groundbreaking work of Max-Neef et al., [20] who introduced the concept of Synergic Satisfiers. Their vision is rooted in the belief that needs can be separated from satisfiers. According to their argumentation, needs are independent of contextual elements such as culture, geography, and social embedding and they are more or less independent of time. Satisfiers, however, are strongly dependent of context and one should aim at the development of solutions that satisfy multiple needs at the same time. As an example they mention breast feeding which satisfies both the need of subsistence as well as the needs of protection, and affection. With their theory, MaxNeef et al., illustrate that human needs can be well integrated with the process of human development.

Based on the framework presented above we arrive at the following informal definition of Synergetic Prosperity:

"Synergetic Prosperity refers to the development and application of eco-affluent innovations that allow all people to flourish"

The key element of the new vision on AmI2.0 is that the development of Ambient Intelligence should be geared towards the development of concepts that can act as Synergic Satisfiers ultimately contributing to Synergetic Prosperity.

\section{Implementing the new vision}

Below we present a number of examples of ambient intelligent concepts that can be viewed as proof points of the existence of synergic satisfiers, thus illustrating contributions of AmI2.0 to Synergetic Prosperity.

\section{Example 1: My Reading Light}

In the beginning of 2009, Philips launched a new ambient intelligent, solar powered, Led based reading light, called 'My Reading Light'. This device enables people to read and write in the dark when the night falls, without using a power grid or disposable batteries. Only in Africa, around half a billion people live without electricity. This means that after sunset, people are barely able to read or study. Candles and kerosene lamps have been the only tools till recently. As a result, children could not study in the evening hours, realising that at the equator night falls around
6PM already. With My Reading Light, people are provided an innovative solution. The costs of the device itself are low, and during daytime, the reading light recharges by using daylight.

\section{My Reading Light [21]}

"Offering new LED based, solar lighting solutions offers a triple-win: the lives of people in Africa will be generally improved, LEDs result in a very low carbon footprint and companies offering the right solutions stand to gain".

My reading light is a fine example of a lighting solution which is ready and usable anywhere, and anytime at zero costs. It contributes to the simultaneous satisfaction of the various elements of Synergetic Prosperity in the following way.

Body: the device enables people to study under physically better circumstances. Candlelight or kerosene lamps are not good for the eyes. Without this product people would only be able to read in bad light in countries and areas that still lack electricity.

Mind: young people are able to study or do their homework in the evening hours, where older people can read for enjoyment or personal development as well. This provides people with knowledge that will result into self enrichment and enrichment of society.

Community: education is the major driver of today's knowledge economy. When new generations can continue education, and go to university, society as a whole will benefit.

Environment: My Reading Light does not need any resources except for the production of it. The device will be charged by daylight, which generates reading light for several hours in the evening, thus enabling people to read or write.

\section{Example 2: TagTiles}

Intelligent Toys helps children to learn social and other kinds of skills while the fun element remains intact. The company Serious Toys produces and sells educational products that match the need for playing and personal development by applying tangible objects in an ambient intelligent setting. TagTiles is an electronic board game where both fine motor skills, cognitive, and social skill are being challenged. The development of (individual) children is the central focus. Children can experiment with different (team) roles in the games at different levels which they select themselves. First results indicate that shy chil- 
dren can become more assertive and accepted by peers [22].

\section{TagTiles [23]}

"TagTiles can be described best as a game computer in the form of a tablet, without keyboard, without mouse, without screen. Children play with the board by placing play pieces on them. It is very easy to use, because the pieces you use to control the computer form an integral part of the game that is played. This makes a task easy to understand and a lot of fun to carry out".

TagTiles contributes to Synergetic Prosperity in the following way.

Body: while playing TagTiles, children develop motoric skills because the game requires to pick-up, touch, and mover objects in a controlled way.

Mind: during the play, children develop cognitive skills improving their learning behavior and developing their intelligence.

Community: TagTiles stimulates children to learn, play, and work together already at an early stage which will be fruitful when they become older and actively participate in society.

Environment: different children can play at the same time with the same device. The device embeds a multitude of games at different levels, so can save in materials compared to 'old-fashioned' toys.

Example 3: MyHeart

The 'MyHeart' project is one of the largest health care research projects within the European Union of the past years. It is aimed at developing concepts for ambient assisted living in relation to heart failure. Within a consortium of 33 partners from industries, knowledge institutes, and governments spread over 10 European countries, research was conducted into a variety of solution related to a number of different aspects of cardio-vascular diseases. With the help of AmI technology, such as wearable electronics and integrated services, vital body functions can be monitored and processed. Cardio-vascular diseases (CVDs) are the major cause of death in our western world. In Europe more than $20 \%$ of the people suffer from chronic cardio-vascular diseases. Around 45\% of all deaths can be related to fatal heart failure. As a result, Europe spends billions of Euro's a year on CVD treatment. Society is aging at grate pace which urgently demands for a healthier and more preventive lifestyle. A different lifestyle in combination with early diagnosis could save us millions of live-years.

\section{MyHeart [24]}

"The MyHeart mission is to empower citizen to fight cardio-vascular diseases by preventive lifestyle and early diagnosis.

The starting point is to gain knowledge on a citizen's actual health status. To gain this info continuous monitoring of vital signs is mandatory. The approach is therefore to integrate system solutions into functional clothes with integrated textile sensors. The combination of functional clothes and integrated electronics and process them on-body, we define as intelligent biomedical clothes. The processing consists of making diagnoses, detecting trends and react on it. Together with feedback devices, able to interact with the user as well as with professional services, the MyHeart system is formed.

This system is suitable for supporting citizens to fight major CVD risk factors and help to avoid heart attack, other acute events by personalized guidelines and giving feedback. It provides the necessary motivation the new life styles. MyHeart will demonstrate technical solutions. The outcome will open up a new mass market for the European industry and it will help prevent the development of CVD, meanwhile reducing the overall EU healthcare costs".

MyHeart contributes to Synergetic Prosperity in the following way.

Body: MyHeart helps people preventing heart diseases, and enables a healthy life style. People are provided with information about how to work on a vital life, enjoy a healthier life, and live longer.

Mind: people will feel more at ease as they know what is good for their body, when they better understand what their lifestyle does with their health and how to improve their health. People are motivated to adopt to a healthy life style.

Community: people will stay healthy longer and they will be able to live independently longer, thus leading to reduced costs of the healthcare system. Furthermore, strengthen the healthy labor force, on the one hand because people can work longer and on the other hand because less people will be disabled to work. 
Environment: MyHeart may result in a substantial reduction of medication thus reducing the footprint of the pharmaceutical industry worldwide. Furthermore, wearable electronics and integrated services contribute to dematerialization.

\section{Example 4: One Laptop per Child}

The association 'One laptop per child' was founded by MIT professor Negroponte. He discovered in 2002 how connected laptops can transform lives of children and their families in remote areas. The mission from One Laptop per Child (OLPC) is: "to empower the children of developing countries to learn by providing one connected laptop to every school-age child. In order to accomplish our goal, we need people who believe in what we're doing and want to help make education for the world's children a priority, not a privilege" [25].

\section{One Laptop per Child [25]}

"A small machine with a big mission. The $\mathrm{XO}$ is a potent learning tool designed and built especially for children in developing countries, living in some of the most remote environments. It's about the size of a small textbook. It has built-in wireless and a unique screen that is readable under direct sunlight for children who go to school outdoors. It's extremely durable, brilliantly functional, energy-efficient, and fun".

Body: children in remote areas are safer, because they do not need to travel large distances anymore to get education.

Mind: the XO supports learning, thus enabling children to educate them selves by collecting knowledge that stimulates their minds and provides meaning to their lives.

Community: by enabling children, but also elder people, with a laptop, people become connected, and can actively participate in today's global society. Next to enabling participation, educated people can also contribute to society by sharing and exploiting their knowledge and skills.

Environment: the XO operates at extremely low energy levels and is environmentally friendly.

This is just an arbitrarily chosen collection of examples that explain the AmI2.0 paradigm related to Synergetic Prosperity. There are currently many more interesting developments that provide ground breaking AmI technologies which eventually may contribute to new Synergetic Prosperity solutions.
One of the most intriguing ones is the MIT's Medialab recently introduced SixthSense [26], "a wearable gestural interface that augments the physical world around us with digital information and lets us use natural hand gestures to interact with that information". The SixthSense seamlessly integrates information with reality, and enables real time interaction with the environment. The challenge is to further develop such prototypes into balanced products that make sense to users and contribute to synergetic prosperity.

\section{Implementing the new vision}

Ten years of development of Ambient Intelligence has raised some serious concerns with respect to its development. Besides technology and user requirements, also economic and socio-political issues have to be taken into account. On the one hand AmI technology makes it possible to provide people with flexible, embedded, and adaptable products and services. On the other hand it should also be about sense-making concepts that result in a balance of body and mind, and community and earth.

Ambient Intelligence requires a new innovation direction that supports the sustainable development of our society. This paradigm is called AmI2.0: Towards Synergetic Prosperity. Synergetic Prosperity will be the key for the future development of Ambient Intelligence. Only when products and services make sense to the users, with the right balance between body, mind, community and earth, Synergetic Prosperity can be realized.

\section{References}

[1] E. Aarts, H. Harwig and M. Schuurmans, Ambient Intelligence, in: The Invisible Future, J. Denning, ed., McGraw Hill, New York, 2001, pp. 235-250.

[2] M. Weiser, The computer for the Twenty-First Century, Scientific American 165(3) (1991), 94-104.

[3] http://cordis.europa.eu/fp7/ict/istag/home_en.html.

[4] ISTAG, Ambient Intelligence: from vision to reality, Report, European Commission, Luxemburg, ftp://ftp.cordis.europa. eu/pub/ist/docs/istag-ist2003_consolidated_report.pdf, 2003.

[5] E.H.L. Aarts and S. Marzano, eds, The New Everyday: Visions on Ambient Intelligence, 010 Publishers, Rotterdam, The Netherlands, 2003.

[6] E.H.L. Aarts and Encarnacao, eds, True Visions: The Emergence of Ambient Intelligence, Springer-Verlag, Berlin, Germany, 2006.

[7] ISTAG, Revising Europe's ICT Strategy, Report, European Commission, Luxemburg, ftp://ftp.cordis.europa.eu/pub/ist/ docs/istag-revising-europes-ict-strategy-final-version en.pdf, 2009. 
[8] E.H.L. Aarts and E. Diederiks, eds, Ambient Lifestyle: From Concept to Experience, BIS Publishers, Amsterdam, 2006.

[9] J. Green, Thinking the unthinkable, in: In the Long Run (Corporate Foresight und Langfristdenken in Unternehmen und Gesellschaft), K. Burmeister and A. Neef (Hrsg.), 2005.

[10] E.H.L. Aarts and B. de Ruyter, New research perspectives on Ambient Intelligence, Journal of Ambient Intelligence and Smart Environments 1(1) (2009), 5-14.

[11] ISTAG, Experience and Application Research: Involving Users in the Development of Ambient Intelligence, Report, European Commission, Luxemburg, $\mathrm{ftp}$ ://ftp.cordis.europa. eu/pub/ist/docs/2004 ear_web_en.pdf, 2004.

[12] K. Feurstein, A. Hesmer, K.A. Hribernik, K.-D. Thoben and J. Schumacher, Living Labs: A new development strategy, in: European Living Labs, J. Schumacher and V.P. Niitamo, eds, Springer Verlag, Berlin, Germany, 2008.

[13] J.E.J. Prins, When personal data, behaviour and virtual identities become a commodity: Would a property rights approach matter? The Icfai Journal of Cyber Law 6(4) (2007), $48-77$.

[14] http://is.jrc.ec.europa.eu/pages/TFS/SWAMI.html.

[15] D. Wright, S. Gutwirth, M. Friedewald, E. Vildjiounaite and Y. Punie, eds, Safeguards in a World of Ambient Intelligence, Springer Verlag, Berlin, Germany, 2008.
[16] K. Ducatel, M. Bogdanowicz, F. Scapolo, J. Leijten and J.C. Burgelman, Scenarios for Ambient Intelligence in 2010, ISTAG report for the European Commission, Luxemburg, 2001.

[17] A. Antonovsky, Health, Stress and Coping, Jossey-Bass, San Francisco, USA, 1979.

[18] S. Aditya, Govt Plans Blueprint for Creative Industries, The Jakarta Post, 2008.

[19] A. Price, Slow Tech: Manifesto for an Overwound World, Atlantic Books, London, United Kingdom, 2009.

[20] M.A. Max-Neef, A. Elizalde and M. Hopenhayn, Development and Human Needs, in: Human Scale Development, Max-Neef, ed., The Apex Press, New York, USA, 1991.

[21] http://www.newscenter.philips.com/about/news/press/20090 216 sesa.page.

[22] K. Hendrix, R. Van Herk, J. Verhaegh and P. Markopoulos, Increasing Children's Competence Through Games, an Exploratory Study, IDC, Como, Italy, 2009.

[23] http://www.serioustoys.com/en/home.aspx.

[24] http://www.hitech-projects.com/euprojects/myheart/.

[25] www.laptop.org.

[26] P. Maes and P. Mistry, Unveiling the "Sixth Sense", Gamechanging Wearable Tech., TED 2009, Long Beach, CA, USA, 2009. 